\title{
РОЛЬ ИЗМЕНЕНИЙ ОКИСЛИТЕЛЬНО-ВОССТАНОВИТЕЛЬНЫХ РЕАКЦИЙ В ПАТОГЕНЕЗЕ ЭНДОТЕЛИАЛЬНОЙ ДИСФУНКЦИИ РАЗНОЙ СТЕПЕНИ ТЯЖЕСТИ ПРИ АРТЕРИАЛЬНОЙ ГИПЕРТОНИИ
}

\author{
(C) Гориунова Н.К., Медведев Н.В., Рахманова О.В.
}

\author{
Кафедра поликлинической терапии и общей врачебной практики \\ Курского государственного медицинского университета, Курск \\ E-mail: gorsh@,kursknet.ru
}

\begin{abstract}
С целью определения роли продуктов окислительного метаболизма липидов, пептидов и нитросоединений в повреждениях сосудистого эндотелия на фоне артериальной гипертонии (АГ) обследованы 58 больных АГ 40-74 лет методами оценки эндотелийзависимой вазодилатации, иммуноферментного анализа, спектрофотометрии, определения активности оксида азота в сыворотке крови с помощью реактива Грисса. Установлено, что тяжесть эндотелиальной дисфункции на фоне АГ зависит от интенсивности окислительных реакций: на ранней стадии происходит интенсивное окисление липидов; позднее присоединяются фазовые изменения содержания уровня нитритов и нитротирозина. Прогрессирование эндотелиальных поражений в начальных стадиях ассоциировано с уровнем общей окислительной активности, а на более поздних - с концентрацией продуктов окисления пептидов, что имеет важное диагностическое и прогностическое значение для оценки выраженности повреждения эндотелия как органа-мишени при АГ.
\end{abstract}

Ключевые слова: эндотелиальная дисфункция, артериальная гипертония, продукты окисления, нитриты.

\section{ROLE OF OXIDATIVE REACTIONS CHANGES IN THE PATHOGENESIS OF ENDOTHELIAL DYSFUNCTION OF DIFFERENT SEVERITY IN ARTERIAL HYPERTENSION Gorshunova N.K., Medvedev N.V., Rakhmanova O.V.}

Department of Polyclinic Therapy and General Practice of Kursk State Medical University, Kursk

In order to determine the role of products of lipid, peptides and nitro compounds oxidative metabolism in damages of vascular endothelium due to arterial hypertension (AH), 58 patients with AH aged 40-74 were examined by methods of endothelium dependent vasodilatation, enzyme immunoassay, spectrophotometry, determination of serum nitric oxide activity with Griss reagent. It was established that the severity of endothelial dysfunction against the background of hypertension depends on the intensity of oxidative reactions: at an early stage, intense oxidation of lipids takes place; Later, phase changes in the content of the nitrites and nitrotyrosine level are added. The progression of endothelial lesions in the initial stages is associated with the level of total oxidative activity, and at later stages with the concentration of oxidation products of peptides, which is of great diagnostic and prognostic value for evaluating the severity of endothelial damage as a target organ in hypertension.

Keywords: endothelial dysfunction, arterial hypertension, oxidation products, nitrites.

По современным представлениям артериальная гипертония (АГ) остается широко распространенным заболеванием, которым страдает более 40\% населения РФ [1]. Она относится к окислительной патологии, в патогенезе которой инициирующей и ключевой ролью считается интенсификация окислительно-восстановительных реакций. В период становления хронической гипертензии кроме нейрогуморальных регуляторных нарушений уже на ранних стадиях происходит формирование поражения сосудистого эндотелия, как одного из главных компонентов сердечнососудистого континуума [10]. Изначально поражения сосудистого эндотелия носят функциональный характер, в первую очередь это касается синтеза и секреции оксида азота - важнейшего биоэффектора вазотонического состояния артериальной сосудистой системы. Последующее прогрессирование эндотелиальных нарушений носит фазовый характер и изменяется от компенсаторного повышения содержания оксида азота и его дериватов - нитратов и нитритов в сыворотке крови - до истощения их продукции в период развития структурных повреждений эндотелия и появления участков деэндотелизации в интиме сосудистой стенки.

Окислительные метаболические изменения как обязательный компонент регуляторного сосудистого стресса и последующих гипоксических влияний приводят к повышению продукции активных форм кислорода (АФК), интенсификации свободно-радикального окисления [2, 10]. Процесс карбонилирования пептидов наиболее ярко проявляется при патологических состояниях, ассоциированных с АГ, таких как хроническая почечная недостаточность (ХПН), ХСН, сахарный диабет и др. [3].

Степень выраженности оксидативных изменений и снижения активности антиоксидантной защиты неодинаковы при АГ 2 стадии и имеют существенное значение в формировании эндотелиальных повреждений разной тяжести. Роль вы- 
раженности процессов пероксидации нитросоединений, пептидов, липидов, их взаимодействия и влияния образующихся продуктов пероксидации на эндотелиоциты мало изучена, особенно в отношении их значимости в развитии эндотелиальной дисфункции разной степени тяжести, что важно для диагностики, прогнозирования течения гипертензивных поражений органов-мишеней и назначения адекватных корригирующих мероприятий.

Цель настоящего исследования - определение роли нарушений окислительно-восстановительных реакций и продуктов окислительного метаболизма липидов, пептидов и нитросоединений в повреждениях сосудистого эндотелия у больных артериальной гипертонией.

Для достижения указанной цели решались задачи оценки переокисления липидов, общей окислительной активности сыворотки крови, продуктов нитрозилирования (нитритов, пероксинитрита), активности дополнительных продуктов окисления пептидов и ключевого фермента антиоксидантной защиты - супероксиддисмутазы (СОД-3) при разных степенях выраженности эндотелиальной дисфункции у больных АГ 2 стадии с уровнем артериальной гипертензии 1-3 степени.

\section{МАТЕРИАЛЫ И МЕТОДЫ ИССЛЕДОВАНИЯ}

Выборка проводилась случайным образом. В простое, открытое, рандомизированное (по степени выраженности эндотелиальной дисфункции) исследование включены 58 пациентов от 40 до 74 лет, страдающих АГ II стадии АГ 1, 2 степени (40 женщин и 18 мужчин), вошедших в основную группу. За 2 недели до начала исследования всем пациентам проведена отмена антигипертензивной терапии за исключением препаратов, применяемых в случае развития гипертензивного криза (капотен, амлодипин).

В соответствии с правилами GCP (Good Clinical Practice), в исследование включались лица, давшие письменное согласие на участие в исследовании и не относящиеся к «уязвимым» социальным группам, таким как беременные женщины, студенты, военнослужащие, больные с тяжелыми неизлечимыми заболеваниями и лица с выраженными нарушениями психики и органов чувств.

Диагноз артериальной гипертонии верифицирован на основании анамнеза, данных объективного, лабораторных и инструментальных методов обследования в соответствии с критериями ВОЗ/МОАГ и рекомендациями Всероссийского медицинского общества по артериальной гипертонии (2016 г.) по диагностике и лечению артери- альной гипертонии [4]. Было учтено наличие сопутствующих заболеваний, отсутствие антигипертензивной терапии или нерегулярный еe характер.

Критерии исключения: вторичные формы АГ, гипертонический криз на момент обследования, острое нарушение мозгового кровообращения и инфаркт миокарда в анамнезе, гемодинамически значимые пороки сердца, нарушения ритма сердца, хроническая сердечная недостаточность III-IV функциональных классов в соответствии с классификацией Нью-Йоркской кардиологической ассоциации (NYHA), сахарный диабет, заболевания щитовидной железы, системные заболевания соединительной ткани, анемии, злокачественные новообразования, патология органов дыхания, мочевыделительной системы и желудочнокишечного тракта в стадии обострения, острые воспалительные заболевания в течение месяца до начала исследования.

Всем пациентам проводилось стандартное общеклиническое и лабораторное обследование, физикальные и антропометрические методы. В биохимический комплекс входило определение уровня общего холестерина (ОХC) и липидных фракций крови: липопротеиды высокой плотности (ЛПВП), липопротеиды низкой плотности (ЛПНП), триглицериды (ТГ). В работе исследовались следующие параметры окислительного метаболизма: общая окислительная активность (ООА), которую оценивали с помощью колориметрического метода определения перекисей в образцах с этилендиаминтетраацетатом (ЭДТА) сыворотки крови набором PerOx, (Германия); уровень малонового диальдегида - показателя выраженности карбонильного стресса измеряли спектрофотометрически с помощью набора «ТБК-Агат» (Россия), продукты окисления белков - методом спектрального анализа модифицированных белков при длине волны 340 нм с помощью набора AOPP Kit Immundiagnostik (Германия), содержание продуктов деградации оксида азота в сыворотке крови - с помощью реактива Грисса.

Степень эндотелиальной дисфункции (ЭД) устанавливали во время допплерографии плечевой артерии с манжеточной пробой для создания реактивной гиперемии с помощью линейного датчика 7,5 МГц ультразвукового аппарата «LOGJQ 7» (Япония). Измерения проводили линейным методом, предложенным D.S. Celermajer и соавт., 1992. Плечевая артерия лоцировалась в продольном сечении на 2-15 см выше локтевого сгиба. Степень дисфункции эндотелия определяли по степени вазодилатации, определяемой по уровню изменения диаметра сосуда в пробе с реактивной гиперемией. Нормальной признавали 
степень дилатации плечевой артерии более чем на $10 \%$ от исходного диаметра, значение показателя от 9-7,5\% расценивали как І степень ЭД, 7,5-3\% как вторую; 3-2\% - как третью; меньше 2\% или выявление вазоконстрикции - как четвертую степень.

Статистический анализ полученных результатов выполнен на персональном IBM-совместимом компьютере с использованием программ Statistica 10.0, BIOSTAT, Microsoft Excel. Для проверки формы распределения изучаемых переменных использован тест Шапиро-Уилка. При распределении, отличном от нормального, они выражались Ме (медианой) и интерквартильным интервалом (25 и 75 процентили). Качественные переменные выражались абсолютными (n) и относительными (\%) значениями. Статистическая обработка выборок с ненормальным распределением осуществлена с использованием непараметрического теста - U-критерия Манна-Уитни. Для пе- ременных с ненормальным распределением проведена многофакторная корреляция Пирсона (r). Различия между сравниваемыми группами признавались статистически значимыми при $\mathrm{p}<0,05$.

\section{РЕЗУЛЬТАТЫ ИССЛЕДОВАНИЯ И ИХ ОБСУЖДЕНИЕ}

Допплерографически с использованием пробы с реактивной гиперемией изучена эндотелийзависимая вазодилатация (ЭЗВД) плечевой артерии у 58 больных АГ. Анализ ЭЗВД был дополнен оценкой состояния свободнорадикальных окислительных и антиокислительных реакций и их влияния на степень выраженности ЭД.

При исследовании ЭЗВД у 7\% больных АГ 2 стадии степень вазодилатации плечевой артерии составила $12,5 \pm 0,5 \%$, что соответствовало 0 степени ЭД.

Таблица 1

Показатели общеклинического, лабораторного обследования больных АГ при разных степенях тяжести ЭД (Ме [25 и 75 процентилей])

\begin{tabular}{|c|c|c|c|c|c|}
\hline Степень ЭД & $\begin{array}{c}0 \text { степень } \\
(\mathrm{n}=4)\end{array}$ & $\begin{array}{c}1 \text { степень } \\
(\mathrm{n}=2)\end{array}$ & $\begin{array}{c}2 \text { степень } \\
(\mathrm{n}=12)\end{array}$ & $\begin{array}{l}3 \text { степень } \\
(\mathrm{n}=14)\end{array}$ & $\begin{array}{c}4 \text { степень } \\
(\mathrm{n}=26)\end{array}$ \\
\hline Показатель & 1 & 2 & 3 & 4 & 5 \\
\hline Возраст & $57[49 ; 68]$ & $65[61 ; 69]$ & $72,5[59 ; 78]$ & $70[60 ; 77]$ & $72[60 ; 79]$ \\
\hline Poct & $161,5[160 ; 173]$ & $172[160 ; 184]$ & $160[157 ; 170]$ & $164,5[162 ; 170]$ & $165[160 ; 170]$ \\
\hline $\mathrm{Bec}$ & $77,5[69 ; 90,5]$ & $88,5[65 ; 112]$ & $85,5[68,5 ; 90,5]$ & $72,5[62 ; 84]$ & $76,5[70 ; 88]$ \\
\hline ИМТ & $28,85[26,4 ; 30,7]$ & $29,2[25,4 ; 33]$ & $29,2[26,8 ; 34,3]$ & $25,8[23 ; 29,7]$ & $27,75[25,4 ; 33]$ \\
\hline САД & $167,5[135 ; 195]$ & $165[140 ; 190]$ & $155[140 ; 167,5]$ & $147,5[140 ; 155]$ & $150[140 ; 160]$ \\
\hline ДАД & $95[85 ; 100]$ & $97,5[85 ; 110]$ & $92,5[85 ; 95]$ & $90[85 ; 95]$ & $90[90 ; 95]$ \\
\hline ПАД & $77,5[50 ; 95]$ & $67,5[55 ; 80]$ & $62,5[55 ; 72,5]$ & $60[50 ; 70]$ & $60[50 ; 65]$ \\
\hline ЧCC & $74[66 ; 79]$ & $69[58 ; 80]$ & $66[60 ; 68]$ & $70[66 ; 72]$ & $70[68 ; 76]$ \\
\hline \% прироста ПА & $12,5[11,4 ; 13]$ & $8,75[8 ; 9,5]$ & $\begin{array}{c}5[4 ; 5,5] \\
\mathrm{p}^{2-3}=0,035\end{array}$ & $\begin{array}{c}3[2 ; 3] \\
\mathrm{p}^{3-4}=0,0001\end{array}$ & $\begin{array}{c}0 \\
\mathrm{p}^{4-5}=0,0001\end{array}$ \\
\hline $\begin{array}{l}\text { Длительность } \\
\text { АГ }\end{array}$ & $10[7 ; 16]$ & $17,5[10 ; 25]$ & $12,5[1 ; 20]$ & $13[8 ; 20]$ & $18,4[12 ; 25]$ \\
\hline Общий бел, г/л & $64,5[62 ; 70]$ & $63,5[60 ; 67]$ & $72[68 ; 79]$ & $71,5[65 ; 77]$ & $72[63 ; 77]$ \\
\hline Альб., г/л & $39[38,5 ; 40]$ & $38[36 ; 40]$ & $38,1[36,6 ; 39,25]$ & $37,3[34,6 ; 39]$ & $37,4[36 ; 40]$ \\
\hline Глобулины, г/л & $\begin{array}{c}22,95 \\
{[20,95 ; 25,45]}\end{array}$ & $\begin{array}{c}24,35 \\
{[22,8 ; 25,9]}\end{array}$ & $\begin{array}{c}28,45 \\
{[25,65 ; 32,05]}\end{array}$ & $\begin{array}{c}25,5 \\
{[24,6 ; 29,6]}\end{array}$ & $\begin{array}{c}27,65 \\
{[24,6 ; 34,2]}\end{array}$ \\
\hline $\begin{array}{l}\text { Холестерин } \\
\text { общий, ммоль/л }\end{array}$ & $4,9[4,8 ; 5,36]$ & $\begin{array}{c}6,06 \\
{[4,82 ; 7,3]}\end{array}$ & $\begin{array}{c}6,005 \\
{[5,01 ; 6,255]}\end{array}$ & $\begin{array}{c}5,11 \\
{[4,96 ; 6,24]}\end{array}$ & $\begin{array}{c}5,96 \\
{[5,4 ; 6,8]} \\
p^{4-5}=0,041\end{array}$ \\
\hline $\begin{array}{l}\text { ЛПВП, } \\
\text { ммоль/л }\end{array}$ & $0,85[0,755 ; 1]$ & $\begin{array}{c}0,885 \\
{[0,81 ; 0,96]}\end{array}$ & $\begin{array}{c}0,74 \\
{[0,59 ; 0,89]}\end{array}$ & $\begin{array}{c}0,71 \\
{[0,57 ; 0,82]}\end{array}$ & $\begin{array}{c}0,68 \\
{[0,59 ; 0,76]}\end{array}$ \\
\hline $\begin{array}{l}\text { ЛПНП, } \\
\text { ммоль/л }\end{array}$ & $\begin{array}{l}2,055[1,63 ; \\
2,66]\end{array}$ & $\begin{array}{c}2,57 \\
{[1,42 ; 3,72]}\end{array}$ & $\begin{array}{c}2,45 \\
{[1,86 ; 2,79]}\end{array}$ & $\begin{array}{c}3,02 \\
{[2,3 ; 3,575]}\end{array}$ & $\begin{array}{c}2,87 \\
{[2,11 ; 3,28]}\end{array}$ \\
\hline ТГ, ммоль/л & $\begin{array}{c}2,175 \\
{[1,355 ; 2,96]}\end{array}$ & $\begin{array}{c}2,62 \\
{[1,92 ; 3,32]}\end{array}$ & $\begin{array}{c}2,16 \\
{[1,94 ; 2,96]}\end{array}$ & $\begin{array}{c}1,845 \\
{[1,68 ; 2,48]}\end{array}$ & $\begin{array}{c}2,625[1,78 ; 3,16] \\
\mathrm{p}^{4-5}=0,047\end{array}$ \\
\hline $\begin{array}{l}\text { Креатинин, } \\
\text { мкмоль/л }\end{array}$ & $79[68 ; 86]$ & $77[63 ; 91]$ & $106[93,5 ; 127]$ & $91,5[81 ; 106]$ & $94,5[79 ; 110]$ \\
\hline $\begin{array}{l}\text { Глюкоза, } \\
\text { ммоль/л }\end{array}$ & $5,2[4,9 ; 6,35]$ & $4,95[4,2 ; 5,7]$ & $5,11[4,48 ; 6,22]$ & $5,16[4,68 ; 5,8]$ & $5[4,8 ; 6,02]$ \\
\hline
\end{tabular}


Показатели окислительной и антиокислительной активности больных АГ при разных степенях тяжести ЭД (Ме [25 и 75 процентилей])

\begin{tabular}{|l|c|c|c|c|c|}
\hline \multicolumn{1}{|c|}{ Степень ЭД } & $\begin{array}{c}0 \text { степень } \\
(\mathrm{n}=4)\end{array}$ & $\begin{array}{c}1 \text { степень } \\
(\mathrm{n}=2)\end{array}$ & 2 степень $(\mathrm{n}=12)$ & $\begin{array}{c}3 \text { степень } \\
(\mathrm{n}=14)\end{array}$ & $\begin{array}{c}4 \text { степень } \\
(\mathrm{n}=26)\end{array}$ \\
\hline \multicolumn{1}{|c|}{ Показатель } & 1 & 2 & 3 & 4 & 5 \\
\hline \multirow{2}{*}{ Нитриты, мкмоль/л } & 3,04 & 3,875 & 3,27 & 2,69 & 3,41 \\
& {$[1,85 ; 4,17]$} & {$[2,64 ; 5,11]$} & {$[2,18 ; 4,3]$} & {$[2,16 ; 3,72]$} & {$[2,39 ; 4,22]$} \\
\hline \multirow{2}{*}{ АОРР, мкмоль/л } & 22,9 & 18,59 & 14,77 & 14,17 & 13,675 \\
& {$[17,4 ; 23,9]$} & {$[14,5 ; 22,6]$} & {$[14 ; 15,43]$} & {$[13,7 ; 15,2]$} & {$[13,1 ; 15,8]$} \\
\hline \multirow{2}{*}{ Нитротирозин, нМ } & 5,2 & 4,2 & 5,6 & 5,11 & 5,36 \\
& {$[4,62 ; 7,26]$} & {$[2,11 ; 6,3]$} & {$[4,56 ; 6,65]$} & {$[4,6 ; 5,38]$} & {$[4,81 ; 7,61]$} \\
\hline \multirow{2}{*}{ РегОх, мкмоль/л } & 179,9 & 237,35 & 318 & 211 & 278 \\
& {$[71,15 ; 283,4]$} & {$[53,71 ; 421]$} & {$[196,5 ; 415]$} & {$[153 ; 275]$} & {$[202 ; 321]$} \\
\hline \multirow{2}{*}{ СОД, нг/мл } & 51,16 & 71,67 & 69,5 & 78 & 73,13 \\
& {$[41 ; 59,85]$} & {$[57 ; 86,3]$} & {$[66 ; 74,5]$} & {$[62 ; 12]$} & {$[62 ; 92]$} \\
\hline \multirow{2}{*}{ МДА, ммоль/л } & 3,26 & 5,07 & 4,26 & 4,19 & 4,26 \\
& {$[2,54 ; 4,61]$} & {$[4,62 ; 5,52]$} & {$[3,9 ; 4,595]$} & {$[3,88 ; 4,69]$} & {$[3,88 ; 4,99]$} \\
\hline
\end{tabular}

У больных АГ с сохраненной регуляцией артериального тонуса по сравнению с соответствующими характеристиками при более выраженных нарушениях эндотелиальной функции регистрировались минимальные значения показателей окислительной и антиокислительной активности (табл. 2).

В проведенном исследовании ЭД 1 степени определена у небольшого числа обследованных больных АГ 2 стадии - всего у $3,5 \%$ со средними значениями ЭЗВД $-8,75 \pm 0,75 \%$. Среди показателей их окислительного метаболизма отмечены резкая интенсификация общей оксидантной активности по показателю PerOx и уровню МДА. Одной из причин развития и прогрессирования ЭД у больных АГ признается субклиническое воспаление, в активации которого важную роль играют реакции свободнорадикального окисления $[7,9]$. Одновременно при ЭД 1 степени наблюдалось повышение активности фермента, позволяющего интегрально оценивать состояние антиоксидантной системы защиты - СОД-3, что сдерживало развитие окислительного стресса, главным критерием которого считается функциональный дисбаланс между оксидантным и антиоксидантным звеньями системы свободнорадикального окисления.

Среди факторов, вызывающих вазодилатацию, ведущая роль принадлежит оксиду азота, окислительные превращения которого регулируют важнейшие функции сосудистой стенки, приводя, в зависимости от выраженности окислительного процесса, к структурным и функциональным повреждениям органов-мишеней, при АГ, в первую очередь сосудов артериального русла [8]. Изменения уровня нитритов ассоциированы с разной степенью выраженности эндоте- лиальной дисфункции $[2,6]$.

При ЭД I степени наблюдалось повышение содержания продуктов окисления оксида азота нитритов до 3,875 мкмоль/л, что подтверждает компенсаторное значение изменений синтеза и секреции NO уже на ранних этапах формирования ЭД.

Дальнейшее окисление метаболитов NO завершается образованием нескольких нитросоединений, одно из которых - пероксинитрит, определяемый в крови по уровню нитротирозина, относится к высокотоксичным клеточным ядам. Концентрация нитротирозина у больных АГ с ЭД I степени была максимальной по сравнению с ее значениями при 2, 3 и даже 4 степенях ЭД, что, по-видимому, связано с разными уровнями синтезируемого NO и неодинаковыми фазами его метаболических модификаций.

При ЭД 2 степени, диагностированной у $11,5 \%$ больных АГ с ЭЗВД, равной 5,0\%, отмечена максимальная активность свободнорадикальных процессов: самая высокая среди больных АГ с другими степенями ЭД общая окислительная активность и повышенный уровень МДА, довольно высокий уровень СОД 3 , а также начинающееся снижение концентрации нитритов, связанное с их расходованием на поддержание вазотонического гомеостаза. Соответственно понижался и уровень нитротирозина, отражая количественные соотношения субстратов нитрозилирования.

У 25\% больных АГ 2 стадии диагностирована ЭД 3 степени с ЭЗВД - 3,0\%. Среди их метаболических окислительных превращений центральное место принадлежало снижению нитритов до $2,9 \pm 0,25$ мкмоль/л (минимальный показатель среди групп с другими степенями ЭД) и соответ- 
ственно наиболее низкому уровню нитрозилирования по показателю нитротирозина. Отмеченные изменения происходили на фоне повышенной общей окислительной и МДА активности по сравнению с аналогичными параметрами у больных с 0 степенью ЭД. Однако показатели нитроокисления свидетельствовали об истощении вышеотмеченных процессов метаболизма NO y больных с 3 степенью ЭД, демонстрируя фазовый характер развития нарушений эндотелиальной функции.

Вместе с тем у обследованной когорты больных АГ с ЭД 3 степени уровень антиоксидантной защиты, определенный по показателю активности супероксиддисмутазы 3, оставался самым высоким по сравнению с концентрацией указанного фермента при других степенях ЭД.

Наиболее выраженные нарушения эндотелиальной функции 4 степени при АГ 2 стадии отмечены у 53\% обследованных больных с крайне низким уровнем ЭЗВД - 0,11 $\pm 0,06 \%$ или патоло- гической вазоконстрикцией. Редокс - состояние этих больных характеризовалось умеренно повышенными показателями общей окислительной и МДА активности, начинающимся незначительным увеличением содержания нитритов в крови, которое по данным литературы может быть связано с их выходом из локальных депо, сопряженностью с активизацией процесса нитроокисления с образованием нитротирозина. Как правило, включенные в исследование больные имели длительный гипертензивный анамнез в среднем $14,5 \pm 1,2$ года, выраженные нарушения липидного обмена в виде гиперхолестеринемии, снижения уровня ЛПВП, дислипопротеинемии за счет повышения ЛПНП, а у части из них и триглицеридов.

На рисунках 1 и 2 представлены изменения показателей окислительно-восстановительного метаболизма в зависимости от степени эндотелиальной дисфункции.

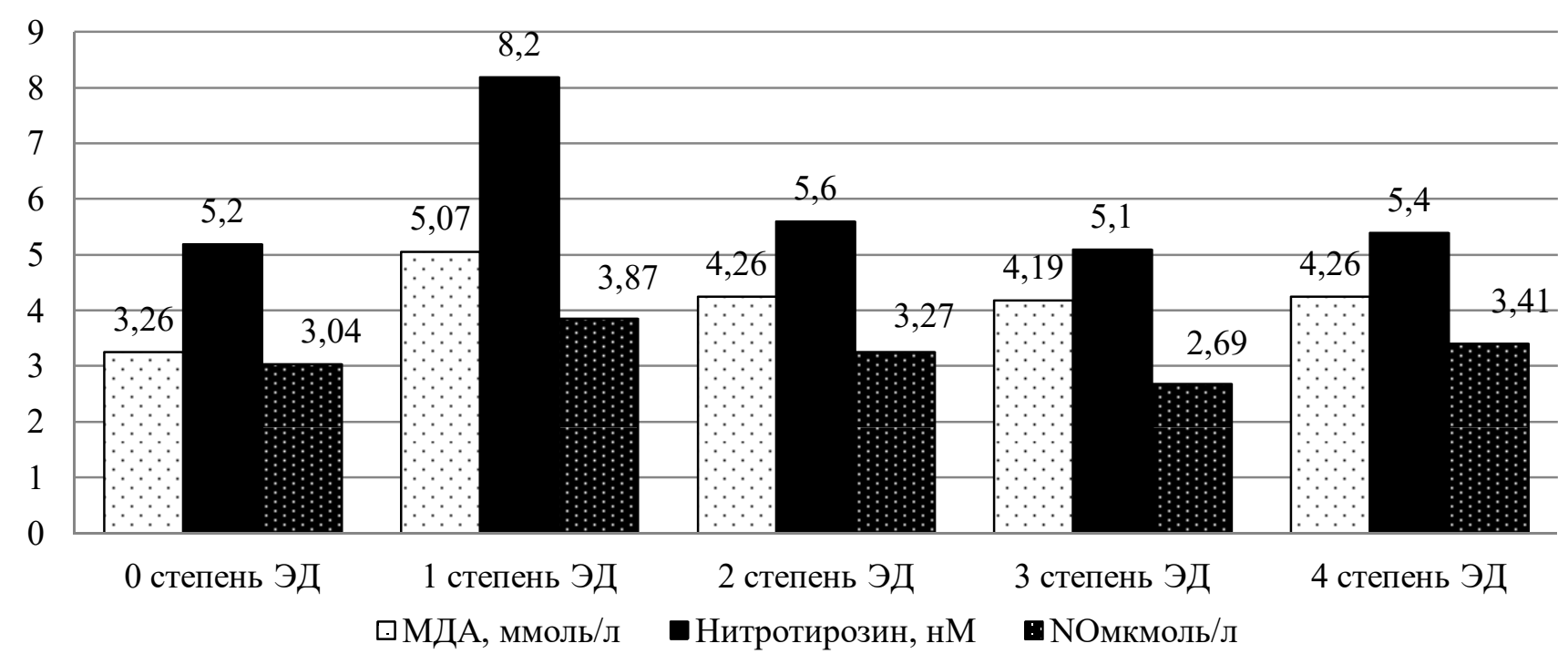

Рис. 1. Показатели продуктов окисления азота и липидов при различной тяжести ЭД.

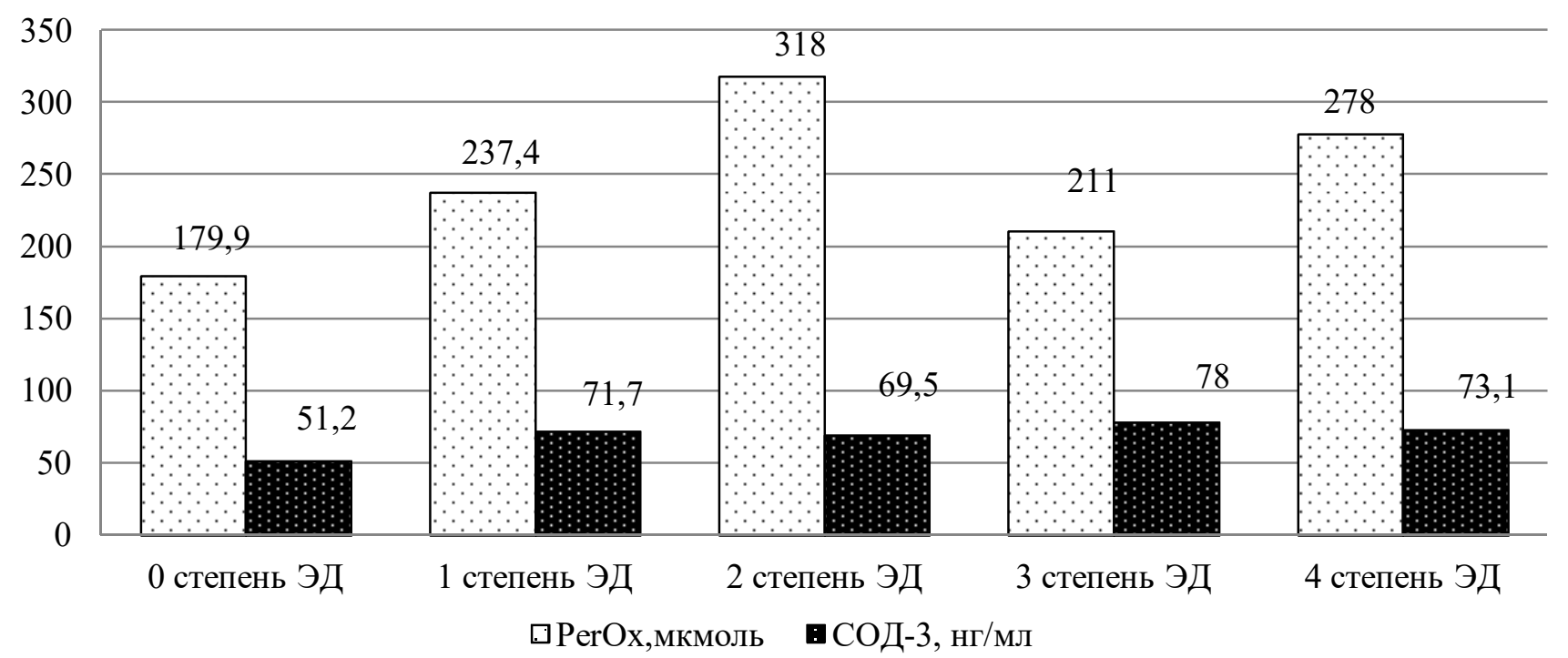

Рис. 2. Уровни окислительной и антиокислительной активности при разных степенях ЭД. 
Отсутствие сведений о значимости окислительных изменений при различной степени нарушения эндотелийзависимой вазодилатации у больных АГ определило следующий этап настоящего исследования. В результате было отмечено повышение активности окислительного процесса у больных АГ 2 стадии при ЭД любой выраженности с пиком ее максимальной активности по тестам PerOx и МДА при ЭД 2 степени. Колебания одного из ведущих регуляторных вазотонических биоэффекторов - оксида азота, определяемого по уровню нитритов, носили фазовый характер: его компенсаторное повышение при ЭД 1 степени, нормальный уровень при ЭД 2 степени, свидетельствующее об истощении NO-синтеза снижение при 3 степени ЭД и небольшое его повышение вследствие выхода из депо при 4 степени ЭД. Концентрации продукта окисления нитритов - нитротирозина прямо зависела от уровня оксида азота, повышаясь при его максимальных значениях.

При ЭД отсутствуют сведения о роли окисления пептидов в развитии и прогрессировании эндотелиальных повреждений. Определение концентрации дополнительных (передовых) продуктов окисления пептидов показали, что их содержание в плазме крови падает по мере увеличения степени повреждения эндотелия и нарушения вазодилатации.

Состояние антиоксидантной защиты с помощью СОД 3 от повреждающего воздействия продуктов окисления, в том числе и нитротирозина (пероксинитрита), по мере прогрессирования ЭД оставалось на одинаковом, слегка повышенном по отношению к больным без эндотелиальных нарушений уровне. Максимальное защитное значение СОД 3 установлено у больных с 2 степенью ЭД, имеющих самую высокую активность окислительных реакций.

У больных АГ при ЭД 1-2 степени прирост вазодилатации на фоне манжеточной пробы прямо коррелировал с уровнем PerOx ( $\mathrm{r}=0,4 ; \mathrm{p}<0,05)$. В группе больных с ЭД 3-4 степени следует отметить положительную корреляцию сосудистой реакции на фоне манжеточной пробы с концентрацией АОРP $(\mathrm{r}=0,33 ; \mathrm{p}<0,05)$. Отмеченные корреляционные связи отражают вклад различных компонентов окислительных реакций в прогрессирование эндотелиальных поражений гипертензивного генеза.

Заключение. Таким образом, тяжесть ЭД на фоне АГ зависела от интенсивности окислительных реакций. При ЭД 1 степени вследствие высокой чувствительности липидов к окислению регистрировался максимальный уровень МДА; изменения содержания нитритов и нитротирозина происходили фазово: наиболее выраженное сни- жение синтеза и секреции NO при ЭД 3 степени было обусловлено высокой концентрацией эндотелий-токсичного нитротирозина на более ранней стадии сосудистого поражения. Максимальной антиоксидантной защитой, оцененной по уровню СОД 3, обладали больные АГ с ЭД 2 степени, несмотря на высокую активность окислительных реакций.

Прогрессирование эндотелиальных поражений в начальных стадиях ассоциировано с уровнем общей окислительной активности, а на более поздних - с концентрацией продуктов окисления пептидов, что имеет важное диагностическое и прогностическое значение для оценки выраженности повреждения эндотелия как органа-мишени при АГ.

\section{ЛИТЕРАТУРА / REFERENCES}

1. Бойцов С.А., Баланова Ю.А., Шальнова С.А., Деев А.Д., Артамонова Г.В., Гатагонова Т.М., Дупляков Д.В., Ефанов А.Ю., Жернакова Ю.В., Конради А.О., Либис Р.А., Минаков А.В., Недогода С.В., Ощепкова Е.В., Романчук С.В., Ротарь О.П., Трубачева И.А., Чазова И.Е., Шляхто Е.В., Карпов Р.С., Кавешников В.С., Серебрякова В.Н., Муромиева Г.А., Евстифеева С.Е., Капустина А.В., Константинов В.В., Оганов Р.Г., Мамедов М.Н., Баранова Е.И., Назарова О.А., Шутемова Е.А., Бабенко Н.И., Фурменко Г.И., Азарин О.Г., Бондариов Л.В., Хвостикова А.Е., Ледяева А.А., Чумачек Е.В., Исаева Е.Н,, Басырова И.Р., Кондратенко В.Ю., Лопина Е.А., Сафонова Д.В., Скрипченко А.Е., Индукаева Е.В., Черкасс Н.В., Максимов С.А., Данильченко Я.В., Мулерова Т.А., Шалаев С.В., Медведева И.В., Шава В.П., Сторожок М.А., Толпаров Г.В., Астахова 3.Т., Тогузова 3.A. Артериальная гипертония среди лиц 25-64 лет: распространенность, осведомленность, лечение и контроль. По материалам исследования ЭССЕ // Кардиоваскулярная терапия и профилактика. - 2014. - Т. 13, № 4. - С. 4-14. [Boytsov S.A., Balanova Yu. A., Shalnova S.A., Deev A.D., Artamonova G.V., Gatagonova T.M., Duplyakov D.V., Efanov A. Yu., Zhernakova Yu.V., Konradi A.O., Libis R.A., Minakov A.V., Nedogoda S.V., Oshchepkova E.V., Romanchuk S.V., Rotar O.P., Trubacheva I.A., Chazova I.E., Shlyakhto E.V., Karpov R.S., Kaveshnikov V.S., Serebryakova V.N., Muromtseva G.A., Evstifeeva S.E., Kapustina A.V., Konstantinov V.V., Oganov R.G., Mamedov M.N., Nazarova O.A., Shutemova E.A.Hаписать письмо aвmopy, Babenko N.I., Furmenko G.I., Bondartsov L.V., Ledyaeva A.A., Chumachek E.V., Isaeva E.N., Basyrova I.R., Lopina E.A., Safonova D.V., Skripchenko A.E., Indukaeva E.V., Cherkass N.V., Maksimov S.A., Danilchenko Ya.V., Mulerova T.A., Shalaev S.V., Medvedeva I.V., Shava V.P., Storozhok M.A., Tolparov G.V., Astakhova Z.T., Toguzova Z.A. Arterial hypertension among individuals of 25-64 years old: prevalence, 
awareness, treatment and control. By the data from ECCD. Kardiovaskulyarnaya terapiya i profilaktika. 2014; 13(4): 4-14 (in Russ.)].

2. Горшунова Н.К., Мауер С.С. Взаимодействие вазотонических биоэффекторов в патогенезе эндотелиальной дисфункции при артериальной гипертензии на фоне старения // Успехи геронтологии. - 2012. T. 25, № 3. - C. 461-467. [Gorshunova N.K., Mauer S.S. Interaction of vasotonic bioeffectors in endothelial dysfunction pathogenesis due to arterial hypertension on aging. Uspekhi gerontologii. 2012; 25(3):461-467 (in Russ.)].

3. Давыдов В.В., Божков А.И. Карбонильный стресс как неспецифический фактор патогенеза (обзор литературы и собственных исследований) // Журнал НАМН Украины. - 2014. - Т. 20, № 1. C. 25-34. [Davydov V.V., Bozhkov A.I. Carbonyl stress is a nonspecific factor of pathogenesis (review of literature and own data). Zhurnal NAMN Ukrainy. 2014; 20(1): 25-34. (in Russ.)].

4. Клинические рекомендации Российского медицинского общества по артериальной гипертонии [Электронный ресурс] // Мирврача.ру. - Режим доступа:

https://mirvracha.ru/article/_arterialnaya_gipertoniya_ u_vzroslykh_klinicheskie_rekomendatsii_rossiyskog o_meditsinskogo_obshchestva_po_arterialnoy_giperto nii_2016_sokrashchennyy_variant/, свободный (14.09.2017). [Clinical recommendations of the Russian medical society on arterial hypertension [Electronic resource]. Mirvracha.ru. Access mode: https://mirvracha.ru/article/_arterialnaya_gipertoniya_ u_vzroslykh_klinicheskie_rekomendatsii_rossiyskog o_meditsinskogo_obshchestva_po_arterialnoy_giperto nii_2016_sokrashchennyy_variant/, free (14/09/2017) (in Russ.)].
5. Ланкин В.3., Тихазе А.К. Важная роль свободнорадикальных процессов в этиологии и патогенезе атеросклероза и сахарного диабета // Кардиология. - 2016. - Т. 56, № 12. - С. 97-105. [Lankin V.Z., Tikhaze A.K. Free Radical Processes Play an Important Role in the Etiology and Pathogenesis of Atherosclerosis and Diabetes. Kardiologiya. 2016; 56(12): 97-105 (in Russ.)].

6. Шишкин А.Н., Льндина М.Л. Эндотелиальная дисфункция и артериальная гипертензия // Артериальная гипертензия. - 2008. - Т. 14, № 4. C. 315-319. [Shishkin A.N., Lyndina M.L. Endothelial dysfunction and hypertension. Arterial'naya gipertenziya. 2008; 14(4): 315-319 (in Russ.)].

7. Franzoni F., Ghiadoni L., Galetta F., Plantinga Y., Lubrano V., Huang Y., Salvetti G., Regoli F., Taddei S., Santoro G., Salvetti A. Physical activity, plasma antioxidant capacity, and endotheliumdependent vasodilation in young and older men // Am J Hypertens. - 2005. - Vol. 18, N 4, Pt 1. P. 510-516. - DOI: 10.1016/j.amjhyper.2004.11.006.

8. Gong $X, M a Y$, Ruan $Y, F u$ G, Wu S. Long-term atorvastatin improves age-related endothelial dysfunction by ameliorating oxidative stress and normalizing eNOS/iNOS imbalance in rat aorta // Exp Gerontol. 2014. - Vol. 52. - P. 9-17. - DOI: 10.1016/j.exger.2014.01.015.

9. Hamilton C.A., Brosnan M.J., McIntyre M., Graham D., Dominiczak A.F. Superoxide excess in hypertension and aging: a common cause of endothelial dysfunction // Hypertension. - 2001. - Vol. 37, N 2, Pt. 2. - P. 529-534.

10. Welch W.J. Angiotensin II-dependent superoxide: effects on hypertension and vascular dysfunction // Hypertension. - 2008. - Vol. 52, N 1. - P. 51-56. - DOI: 10.1161/HYPERTENSIONAHA.107.090472. 